\title{
Services use by children and parents in multiproblem families
}

\author{
Noortje M. Pannebakker ${ }^{\mathrm{a}, *}$, Paul L. Kocken ${ }^{\mathrm{a}, \mathrm{b}}$, Meinou H.C. Theunissen ${ }^{\mathrm{a}}$, Krista van Mourik ${ }^{\mathrm{b}}$, \\ Matty R. Crone ${ }^{\mathrm{b}}$, Mattijs E. Numans ${ }^{\mathrm{b}}$, Sijmen A. Reijneveld ${ }^{\mathrm{c}}$ \\ a Department of Child Health, TNO, The Netherlands \\ ${ }^{\mathrm{b}}$ Department of Public Health and Primary Care, Leiden University Medical Center, The Netherlands \\ ${ }^{\mathrm{c}}$ Department of Health Sciences, University Medical Center Groningen, The Netherlands
}

\section{A R T I C L E I N F O}

\section{Keywords:}

Multiproblem families

Access to care

Health seeking behavior

Social support

\begin{abstract}
A B S T R A C T
Background: Multiproblem families are multi-users of psychosocial and health care services, but little is known about factors associated with their care utilization in the general population. The aim of this study was to assess which factors were associated with the overall and psychosocial care use of two members-i.e., child and parent-of each multiproblem family.

Methods: During well-child visits or psychosocial care, we identified 354 children and their parents who had problems in several life domains (response 69.1\%). We used multivariate stepwise backward logistic regression analyses to identify the factors related to their use of overall and psychosocial care.

Results: A child's overall care use was associated with greater social support from family and friends (odds ratio, OR, 95\% confidence interval, CI; OR $=1.05, \mathrm{CI}=1.01-1.08$ ) compared to less perceived social support; and with more psychosocial problems in the child $(\mathrm{OR}=1.84, \mathrm{CI}=1.04-3.24)$. Child's psychosocial care use was more likely among older children $(\mathrm{OR}=1.94$, CI $=1.20-3.15)$; greater social support by family and friend $(\mathrm{OR}=1.03, \mathrm{CI}=1.00-1.06)$; more psychosocial problems $(\mathrm{OR}=1.75, \mathrm{CI}=1.04-2.97)$; and when there were more parenting concerns $(\mathrm{OR}=1.19, \mathrm{CI}=1.06-1.33)$. Parental overall and psychosocial care use was more likely when the family experienced a higher number of life events $(\mathrm{OR}=1.27, \mathrm{CI}=1.17-1.38$, and $\mathrm{OR}=1.39$, $\mathrm{CI}=1.25-1.55)$.

Conclusions: Care use in multiproblem families is related to family factors as well as psychosocial problems. It may be possible to use these family risk factors to identify such families early, whose intensive care use is possibly explained by the relationship with inadequate use of social support.
\end{abstract}

\section{Introduction}

Multiproblem families have problems in several areas of life, including poverty and psychosocial problems (Tausendfreund, KnotDickscheit, Post, Knorth, \& Grietens, 2014). Children raised in such families run a high risk of poor mother-child attachment and of developing behavior and emotional problems (Denholm, Power, Li, \& Thomas, 2013; Lucas, McIntosh, Petticrew, Roberts, \& Shiell, 2008; Stith et al., 2009). Typically, these children and parents are multi-users of psychosocial care, such as social and mental healthcare. Research shows that these services spend up to $86 \%$ of their budgets on multiproblem families (Goerge, Smithgall, Seshadri, \& Ballard, 2010; Sacco, Twemlow, \& Fonagy, 2008).

Several western countries have developed policies and programmes dealing with families with multiple problems, e.g. the 'Troubled families' programme in the United Kingdom (Hayden \& Jenkins, 2014), the 'One family, one plan, one care coordinator' programme in The Netherlands (NJI, 2011) and 'Wrap around care' in the Unites States of America (Bruns, Burchard, \& Yoe, 1995). These initiatives aim to develop more efficient pathways to care for multiproblem families. Less focus lies on understanding the mechanisms behind the help seeking behavior of families (Morris, 2013). Insight into the reasons behind care use of multiproblem families will improve our understanding of their care seeking behavior which may help to break the intergenerational cycle of intensive care use.

A framework for understanding the factors associated with care use of multiproblem families is provided by Andersen and Newman's behavioral-health model of access to care (Andersen \& Newman, 1973). The Andersen framework determines access to care on the basis of 1 . predisposing factors or an individual's characteristics or abilities to use a specific service (such as, gender, age and cultural identity); 2. enabling factors or means whereby a family accesses care (for example,

\footnotetext{
* Corresponding author at: TNO Child Health, P.O. Box 3005, 2301 DA Leiden, The Netherlands.

E-mail address: noortje.pannebakker@tno.nl (N.M. Pannebakker).
} 
social support or practical barriers to care); and 3. healthcare needs (for example, a child's emotional or behavioral problems). We chose for this framework because it addresses multiple domains from a services user point of view. Goldberg and Huxley's framework pathways to care is another well used framework for understanding care use (Goldberg \& Huxley, 1980). The pathways to care of multiproblem families from a provision of services point of view has already been mapped according to this framework (Hayden \& Jenkins, 2014; Hayden \& Jenkins, 2015). We feel that Andersen and Newman's dual emphasis on individual and family factors is a better starting point for understanding the complex and often intergenerational problems of multiproblem families.

This study aims to understand the mechanisms underlying care use by multiproblem families, which may lead to better support for children raised in these families. This requires research into a broad range of parents' and children's use of services such as mental health and social care services, debt counseling, general practitioners, and medical specialists (Wölfle et al., 2014). The research question was: which factors of the Andersen and Newman's model are associated with overall and psychosocial care use of two members - i.e. child and parent- of each multiproblem family? For this explorative study, we selected factors based on the literature on care use by children with psychosocial problems (Nanninga, Jansen, Knorth, \& Reijneveld, 2015; Verhulst \& Van Der Ende, 1997) and multiproblem families (Goerge et al., 2010; Tausendfreund, Knot-Dickscheit, Schulze, Knorth, \& Grietens, 2016). We expected that the factors associated with care use reflected the multiple domains of problems of these families and include not only need but also predisposing and enabling factors.

\section{Methods}

This study is part of a cohort study on service use and its determinants among multi-problem families in an urban setting in the Netherlands. We used a cross-sectional design to study correlates of children and parents' care use. The study was conducted according to the Helsinki regulation. The Medical Ethics Committee of Leiden University assessed our study proposal and concluded that approval was not required under Dutch Law (C12.041).

\subsection{Sample and procedure}

The aim of our study was to better understand the mechanism underlying care use by multiproblem families. To reach this aim, we wanted to include multiproblem families among which the use of services varied. Therefore we took two samples: 1 . a community sample of multiproblem families who did and did not use care and 2. an added sample of high care use multiproblem families to ensure that care users were sufficiently represented. For the sample of the general population children aged between 18 months and 12 years had been identified during well-child visits. In the Netherlands these well-child visits are provided by preventive youth health care services and have a attendance rate of $95 \%$ for children in our age-sample (CBS, 2014). The sample with a high risk of care use consisted of families enrolled in child and family focused specialist psychosocial care services.

Families were included if they met one of the following criteria: 1. the presence in children aged 3-12 years of psychosocial problems as indicated by elevated scores on the routinely collected parent-reported Strengths and Difficulties Questionnaire (SDQ) (Goodman, 1997) or, in younger children, the psychosocial problems indicated by the professional who made the assessment; 2 . the identification by the preventive child healthcare worker of persistent parenting concerns; 3 . the occurrence of one or more major life event during the past year; and 4. the use of care due to any of the previous criteria.

A total of 512 parents received a digital questionnaire or were interviewed by telephone in the language of their preference, 354 of whom (69.1\%) participated. Of these 354 parents, 45 parents were part of the extra sample of users of psychosocial care services. Two or more of the inclusion criteria were met by $96 \%$ of the parents, these parents are part of the final sample, from hereon called the multiproblem family. Four out of five respondents met three or more inclusion criteria. In only $7 \%$ of the respondents care use was combined with one other inclusion criterion. In $93 \%$ combinations of the other criteria, in addition to care use, were decisive for inclusion.

We do not know the reasons of non-respondents for not answering the invitation to fill in the questionnaire, despite their initial consent to participate. In the non-response group, compared to the response group, children were slightly younger ( 4.8 vs. 5.9 years, $\mathrm{p}<0.001$ ) and more parents had a low socioeconomic position based on their neighborhood (73.4\% vs. $37.9 \%, \mathrm{p}<0.001$ ) (SCP, 2015).

\subsection{Measures}

Service use was measured as overall and psychosocial care use of a child from a multiproblem family in the previous six months. We also measured the overall and psychosocial care use of the child's parent. Overall care use involved any use of care and service delivered in the psychosocial or medical domain in the previous six months, e.g. by the general practitioner, paramedical services (e.g., physiotherapist), medical specialist, mental healthcare services, social care services, school care services or family services. The latter four types of care were also the components of psychosocial care use, which was defined as care use due to psychosocial problems. Overall care use was dichotomized as care or no care use, and psychosocial care as using psychosocial care versus using no care or using other types of care. All four dependent variables were measured using a framework adapted from the Trimbos/Imta questionnaire for costs associated with psychiatric illnesses (also known as TIC-P) (Hakkaart-Van Roijen, Van Straten, Donker, \& Tiemens, 2002).

Predisposing factors involved a child's gender and age, parents' educational level, household composition, ethnic identity as perceived by the parent, and the adverse life events they had experienced. Life events such as unemployment or loss of a loved one in the past 12 months were measured on the life-events scale of the Brief Instrument Psychological and Pedagogical Problem Inventory or KIPPPI (Cronbach's $\alpha=0.79$ ) (De Wolff, Theunissen, Vogels, \& Reijneveld, 2013).

Enabling factors included social support and care use by another family member. To measure social support, we used two subscales of the Dutch Family questionnaire (Van der Ploeg \& Scholte, 2008): 1. "social functioning of the family" (Cronbach's $\alpha=0.91$ ) and 2. "relationship with partner" (Cronbach's $\alpha=0.83$ ). A child's care use was the enabling variable of the parent's dependent variables, and a parent's care use was the enabling variable of the child's dependent variables.

Need factors included a child's health, emotional and behavioral problems, and the parent's mental health and parenting concerns. A child's chronic health conditions involved the parent's response to the following question "Does your child suffer from one or more chronic health conditions—such as asthma, diabetes, ADHD or autism-for which treatment is or was needed?". A child's behavioral and emotional problems were measured using the Brief Infant-Toddler Social and Emotional Assessment (BITSEA) for children aged between 18 months and 3 years (Briggs-Gowan, Carter, Irwin, Wachtel, \& Cicchetti, 2004) and the Strengths and Difficulties Questionnaire (SDQ) for children aged between 3 and 12 years (Goodman, 1997); the validated Dutch versions of both were found to be reliable (Cronbach's $\alpha$ 's of the subscales SDQ ranging from 0.57 to 0.82 and Cronbach's $\alpha$ 's of the subscales BITSAE are 0.79 and 0.62) (Kruizinga et al., 2012; Theunissen, Vogels, De Wolff, \& Reijneveld, 2013). Parental mental health status was measured using the 12-item version of the General Health Questionnaire (GHQ12) (Cronbach's $\alpha=0.87$ ) (Koeter \& Ormel, 1991). Finally, parenting concerns were assessed using the following question "Did you have concerns about your parenting in the past 12 months?" (Zeijl, Crone, Wiefferink, Keuzenkamp, \& Reijneveld, 2005). 


\subsection{Analysis}

To impute missing values, we used predictive mean matching. The proportion of missings on the independent variables ranged from 0 to $2 \%$. There were no missing values for the dependent variables. We used multivariate imputation by chained equations to create 10 imputed data sets based on the predisposing, enabling and need factors specified above (van Buuren, 2012). Uncertainty about the model estimates was reflected in differences between imputations in the different completed data sets.

After describing the background characteristics of the parents and children in the sample of multiproblem families, we used logistic regression analysis to assess the univariate associations between predisposing, enabling or need factors with the child's and parent's overall and psychosocial care use. Finally, to enter the variables in multivariate models, we used stepwise backward logistic regression analyses, entering variables that were significantly related with overall and psychosocial care use at univariate level, or were hypothesized on theoretical grounds to be important to care use. The criterion for keeping a variable in the backward regression model was set at a p-value $\geq 0.05$. Confidence intervals for the outcomes were estimated by pooling results from the imputed data sets (Rubin, 1987). All statistical analyses were performed in SPSS version 20.0 for Windows (IBM Corp, 2011).

\section{Results}

\subsection{Characteristics of the respondents}

Table 1 shows the characteristics of the sample. In the previous six months, three-quarters of the children and under half the parents had reported overall care use, and half the children and one fifth of the parents had used psychosocial care.

Table 1

Respondents' background characteristics and care use.

\begin{tabular}{|c|c|c|}
\hline & & $\begin{array}{l}\text { Total } \\
\text { n }(\%)^{\mathrm{c}}\end{array}$ \\
\hline \multirow[t]{2}{*}{ Child's gender } & Boy & $196(58.9)$ \\
\hline & Girl & $137(41.1)$ \\
\hline \multirow[t]{2}{*}{ Child's age $^{\mathrm{a}}$} & Pre-school & $126(37.8)$ \\
\hline & School-aged & $207(62.2)$ \\
\hline \multirow[t]{2}{*}{ Parent's gender } & Man & 39 (12.7) \\
\hline & Women & $291(87.3)$ \\
\hline \multirow[t]{2}{*}{ Parent's age } & $<36$ & $171(51.4)$ \\
\hline & $\geq 36$ & $162(49.6)$ \\
\hline \multirow[t]{3}{*}{ Parent's educational level ${ }^{\mathrm{b}}$} & Low & $22(6.7)$ \\
\hline & Medium & $156(47.3)$ \\
\hline & High & $152(46.1)$ \\
\hline \multirow[t]{3}{*}{ Parent's cultural identity } & Dutch & $242(74.2)$ \\
\hline & Western & $46(14.1)$ \\
\hline & Non-western & 38 (11.7) \\
\hline \multirow[t]{2}{*}{ Household composition } & Intact families & $292(88.5)$ \\
\hline & Divorced families & $38(11.5)$ \\
\hline \multirow[t]{2}{*}{ Child's care use } & Use of care & $260(78.1)$ \\
\hline & No use of care & $73(21.9)$ \\
\hline \multirow[t]{2}{*}{ Child's psychosocial care use } & Use & $189(56.8)$ \\
\hline & No use & $144(43.2)$ \\
\hline \multirow[t]{2}{*}{ Parent's care use } & Use & 145 (43.5) \\
\hline & No use & $188(56.5)$ \\
\hline \multirow[t]{2}{*}{ Parent's psychosocial care use } & Use & $74(22.2)$ \\
\hline & No use & $259(77.8)$ \\
\hline
\end{tabular}

a Pre-school: 15-47 months; school-aged: 4-12 years.

b "Low level" entails no, primary or lower secondary education, "average level" entails upper secondary education or post-secondary non-tertiary education, and "high level" entails tertiary education.

${ }^{\mathrm{c}} \mathrm{n}$ varies due to missing data.

\subsection{Factors associated with care use}

Table 2 shows our findings regarding children in multiproblem families, i.e., the univariate and mutually adjusted associations between various determinants of care use and overall and psychosocial care use. The final model of overall care use showed that children used overall care significantly more when social support from family and friends was higher and when the child had an elevated score for psychosocial problems. With each unit increase in the score on the social support scale the odds of using overall care increased 5\%. Children with psychosocial problems had $84 \%$ odds higher overall use of care than children without such problems.

The use of psychosocial care was higher in school-aged children, those whose parents had more social support from family and friends, those with an elevated score on psychosocial problems and when the parents reported more parenting concerns. With each additional life event and each additionally reported area of parenting concern the odds of using psychosocial care by the child increased by $94 \%$ and $19 \%$, respectively. With each unit increase in the score on the scale of social support, the odds increased by $3 \%$. The odds of using care were $94 \%$ higher when the child was of school-age compared to pre-school age and $75 \%$ when the child had psychosocial problems, compared to not having problems.

Table 3 shows our finding with regard to parents in a multiproblem family, i.e., the univariate and the mutually adjusted associations of various determinants of care use with overall and psychosocial care use. The final model of overall and psychosocial care use showed that parents reported more overall care use when they had experienced more life events. With each life event the odds of using overall or psychosocial care by the parent increased by $27 \%$ and $39 \%$ respectively.

\section{Discussion}

This study shows that use of care by multiproblem families was related to a series of factors from the Andersen and Newman model of care use. For children of these families, the use of care was associated with an enabling factor (social support provided by family and friends) and a need factor (psychosocial problems of the child). Psychosocial care use was associated with the same two factors, plus a predisposing factor (the child's age) and a second need factor (parenting concerns). Parents' overall and psychosocial care use was related to the predisposing factor adverse life events.

We found life events, a predisposing factor, to be associated with child's and parent's care use in multiproblem families. Life events are a known trigger for care use by children and adults alike (Donga, Andaa, Felitti, \& Dubea, 2004; Norman et al., 2012). Members of a multiproblem family are more likely than people in the general population to experience traumatic and stressful life events such as, domestic violence (Fernandez, 2007). The combinations of multiple adverse life events increase the risk of developing problems and may explain the association between life events and these children's and parents' care use (Finkelhor, Ormrod, \& Turner, 2007; Ghosh Ippen, Harris, Van Horn, \& Lieberman, 2011; Hughes et al., 2017). Adverse life events may thus be a core factor in multiproblem families' use of care.

The positive relationship between the enabling factor social support by family and friends and a child's overall and psychosocial care use aligns with other studies on multiproblem families (Sousa, 2005). Sousa and Rodrigues (2009) found that such families' social networks are usually wide, and that while this seems to help families overcome daily difficulties, it does not generate long-term improvements in their lives. Despite their wide social network, these families also use formal care to compensate for the shortfalls in the social support provided by their family and friends. This may explain their high care use (Matos \& Sousa, 2004). Support from the social network and from care utilization seem to be parallel processes in the problem solving behavior of multiproblem families. 
Table 2

Univariate and multivariate associations of predisposing, enabling, and need factors with overall and psychosocial care use by children from multiproblem families.

\begin{tabular}{|c|c|c|c|c|}
\hline & \multicolumn{2}{|l|}{ Overall care use } & \multicolumn{2}{|c|}{ Psychosocial care use } \\
\hline & OR $(95 \% \mathrm{CI})^{\mathrm{b}}$ & Adj. OR $(95 \% \mathrm{CI})^{\mathrm{cd}}$ & OR $(95 \% \mathrm{CI})^{\mathrm{b}}$ & Adj. OR $(95 \% \mathrm{CI})^{\mathrm{ce}}$ \\
\hline \multicolumn{5}{|l|}{ Predisposing factors } \\
\hline \multicolumn{5}{|l|}{ Child's gender } \\
\hline Girl (vs. male) & $1.19(0.70-2.03)$ & & $1.04(0.67-1.61)$ & \\
\hline \multicolumn{5}{|l|}{ Child's age $^{\mathrm{a}}$} \\
\hline School-age (vs. pre-school) & $1.21(0.71-2.06)$ & & $2.33(1.96-3.70)$ & $1.94(1.20-3.15)$ \\
\hline \multicolumn{5}{|l|}{ Parent's educational level } \\
\hline Average (vs. low) & $0.51(0.12-2.22)$ & & $0.80(0.31-2.05)$ & \\
\hline High (vs. low) & $0.34(0.08-1.48)$ & & $0.52(0.20-1.32)$ & \\
\hline \multicolumn{5}{|l|}{ Parent's cultural identity } \\
\hline Western (vs. Dutch) & $0.56(0.27-1.20)$ & & $0.49(0.25-0.98)$ & \\
\hline Non-western (vs. Dutch) & $0.70(0.34-1.46)$ & & $0.81(0.43-1.55)$ & \\
\hline \multicolumn{5}{|l|}{ Household composition } \\
\hline Intact (vs. divorced) & $1.01(0.92-1.11)$ & & $2.03(0.97-4.27)$ & \\
\hline Number of life events & $1.29(1.19-1.40)$ & & $1.13(1.04-1.22)$ & \\
\hline \multicolumn{5}{|l|}{ Enabling factors } \\
\hline \multicolumn{5}{|l|}{ Partner's social support } \\
\hline & $1.00(0.97-1.05)$ & & $0.97(0.93-1.00)$ & \\
\hline \multicolumn{5}{|l|}{ Social support by family and friends } \\
\hline & $1.04(1.01-1.07)$ & $1.05(1.01-1.08)$ & $1.01(0.98-1.03)$ & $1.03(1.00-1.06)$ \\
\hline \multicolumn{5}{|l|}{ Parent's care use } \\
\hline Use (vs. no use) & $1.58(0.92-2.71)$ & & $1.50(0.96-2.33)$ & \\
\hline \multicolumn{5}{|l|}{ Need factors } \\
\hline \multicolumn{5}{|l|}{ Child's chronic health problems } \\
\hline Problems (vs. no problems) & $1.60(0.83-3.06)$ & & $1.42(0.85-2.36)$ & \\
\hline \multicolumn{5}{|l|}{ Child's psychosocial problems } \\
\hline Problems (vs. no problems) & $1.50(0.88-1.53)$ & $1.84(1.04-3.24)$ & $2.52(1.61-3.95)$ & $1.75(1.04-2.97)$ \\
\hline \multicolumn{5}{|l|}{ Parent's mental health problems } \\
\hline & $0.94(0.87-1.02)$ & & $1.01(0.94-1.09)$ & \\
\hline \multicolumn{5}{|l|}{ Parenting concerns } \\
\hline & $1.04(0.94-1.16)$ & & $1.21(1.10-1.33)$ & $1.19(1.06-1.33)$ \\
\hline
\end{tabular}

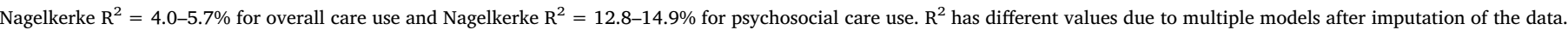

${ }^{\text {a }}$ Pre-school: 15-47 months; school-aged: 4-12 years.

${ }^{\mathrm{b}}$ Univariate regression entering one independent variable in the model.

${ }^{c}$ Stepwise backward logistic regression analysis entering all univariate variables in the model. The criterion for taking a variable out of the model was set at p-value $>0.05$.

d The order in which a variable was removed from the adjusted model was life events, cultural identity, child's age, child's chronic health problem, child's gender, partner's social support, household composition, parenting concerns, parent's educational level, parent's mental health problems, parent's care use.

e The order in which a variable was removed from the adjusted model was child's chronic health problems, partner's social support, child's gender, parent's cultural identity, parent's educational level, household composition, parent's care use, parent's mental health problems, life events.

Although need factors were associated with children's care use, they were absent from the final models for parents. In line with earlier research, parent's care use was significantly associated at univariate level with parental mental health problems and parenting concerns (Ford, Hamilton, Meltzer, \& Goodman, 2008; Travassos, Viacava, Pinheiro, \& Brito, 2002). In our final models, these associations were confounded by life events. The lack of an association with a parent's care use may be explained by the fact that many parents in our study had mild to severe mental health problems.

The relationship with the variables degree of child psychosocial problems and parenting concerns was consistent with that found in other research on the care use of children with emotional, behavioral or mental health problems (Raphael, Zhang, Liu, \& Giardino, 2010; Stahmer et al., 2005; Tick, Van Der Ende, \& Verhulst, 2008). We found that need factors are not the sole determinants associated with care use for children of multiproblem families in which predisposing and enabling factors are also associated with care use.

\subsection{Strengths and limitations}

A strength of this study is that we used a broad sampling strategy to fully include the wide range of multiproblem families, and not just those that had reached care services aiming at high-risk groups. Another strength is that we included families not enrolled in care: earlier studies of care use by these families were limited to families that were already using social and mental health care services (Bodden \&
Dekovic, 2015).

A limitation is the use of a self-report questionnaire for care use, which may have led us to underestimate overall and psychosocial care use; information on the use of psychosocial care services is not yet uniformly registered in the Netherlands. Moreover, we mostly obtained information from mothers (88\%), which may imply that we missed some of the paternal perspective, even though mothers and fathers did not differ statistically on the dependent variables (care use). Another limitation is the cross-sectional design of this study, which limited our potential for making causal inferences.

\subsection{Implications for practice}

Professionals in psychosocial care find it challenging to identify multiproblem families in an early stage of the treatment (Bodden \& Dekovic, 2015). The relevant factors for care use found in this study will help the professionals with this identification. We found that life events is at univariate level associated with the care use of both the child and the parent: it is already clear from earlier studies that it is not so much the severity of the stressors that makes families use care, but more the multitude and combination of adverse life events (Appleyard, Egeland, van Dulmen, \& Sroufe, 2005; Finkelhor et al., 2007; Hughes et al., 2017). This implies that when a child enrolls in care, an important part of the assessment should be to screen for the presence of various life events.

We also found that multiproblem families are likely to report both 
Table 3

Univariate and multivariate associations of predisposing, enabling and need factors with overall and psychosocial care use by parents in multiproblem families.

\begin{tabular}{|c|c|c|c|c|}
\hline & \multicolumn{2}{|l|}{ Overall care use } & \multicolumn{2}{|c|}{ Psychosocial care use } \\
\hline & OR $(95 \% \mathrm{CI})^{\mathrm{b}}$ & Adj. OR $(95 \% \mathrm{CI})^{\mathrm{cd}}$ & OR $(95 \% \mathrm{CI})^{\mathrm{b}}$ & Adj. OR $(95 \% \mathrm{CI})^{\text {ce }}$ \\
\hline \multicolumn{5}{|l|}{ Predisposing factors } \\
\hline \multicolumn{5}{|l|}{ Child's gender } \\
\hline Girl (vs. male) & $1.35(0.87-2.10)$ & & $1.57(0.93-2.63)$ & \\
\hline \multicolumn{5}{|l|}{ 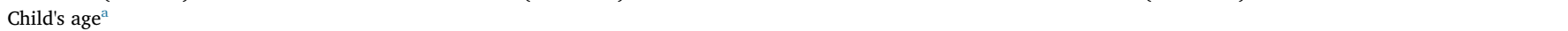 } \\
\hline School-age (vs. pre-school) & $0.97(0.62-1.53)$ & & $1.06(0.62-1.82)$ & \\
\hline \multicolumn{5}{|l|}{ Parent's educational level } \\
\hline Average (vs. low) & $0.74(0.30-1.81)$ & & $0.52(0.21-1.32)$ & \\
\hline High (vs. low) & $0.62(0.25-1.53)$ & & $0.31(0.12-0.79)$ & \\
\hline \multicolumn{5}{|l|}{ Parent's cultural identity } \\
\hline Western (vs. Dutch) & $1.03(0.52-2.07)$ & & $1.62(0.76-3.44)$ & \\
\hline Non-western (vs. Dutch) & $1.08(0.58-2.03)$ & & $0.91(0.42-1.98)$ & \\
\hline \multicolumn{5}{|l|}{ Household composition } \\
\hline Intact (vs. divorced) & $1.37(0.70-2.68)$ & & $1.88(0.91-3.89)$ & \\
\hline \multicolumn{5}{|l|}{ Number of life events } \\
\hline & $1.27(1.17-1.38)$ & $1.27(1.17-1.38)$ & $1.39(1.25-1.53)$ & $1.39(1.25-1.55)$ \\
\hline \multicolumn{5}{|l|}{ Enabling factors } \\
\hline \multicolumn{5}{|l|}{ Social support by partner } \\
\hline & $0.95(0.91-0.98)$ & & $0.93(0.89-0.97)$ & \\
\hline \multicolumn{5}{|l|}{ Social support by family and friends } \\
\hline & $1.00(0.97-1.02)$ & & $0.96(0.93-0.94)$ & \\
\hline \multicolumn{5}{|l|}{ Child's ${ }^{\mathrm{b}}$ care use } \\
\hline Use (vs. no use) & $1.58(0.92-2.71)$ & & $1.64(0.83-3.23)$ & \\
\hline \multicolumn{5}{|l|}{ Need factors } \\
\hline \multicolumn{5}{|l|}{ Child's chronic health problems } \\
\hline Problems (vs. no problems) & $0.95(0.57-1.56)$ & & $0.88(0.48-1.62)$ & \\
\hline \multicolumn{5}{|l|}{ Child's psychosocial problems } \\
\hline Problems (vs. no problems) & $1.00(0.65-1.55)$ & & $1.42(0.85-2.40)$ & \\
\hline \multicolumn{5}{|l|}{ Parent's mental health problems } \\
\hline & $1.10(1.02-1.18)$ & & $1.09(1.01-1.18)$ & \\
\hline \multicolumn{5}{|l|}{ Parenting concerns } \\
\hline & $1.13(1.04-1.23)$ & & $1.17(1.06-1.29)$ & \\
\hline
\end{tabular}

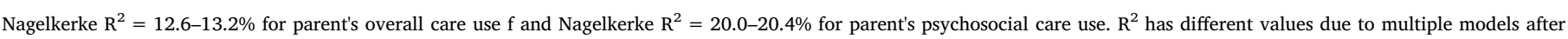
imputation of the data.

a Pre-school: 15-47 months; school-aged: 4-12 years.

b Univariate regression entering one independent variable in the model.

${ }^{\mathrm{c}}$ Stepwise backward logistic regression analysis entering all univariate variables in the model. The criterion for taking a variable out of the model was set at p-value $>0.05$.

d The order in which a variable was removed from the adjusted model was parent's educational level, cultural identity, child's chronic health problems, child's age, child's gender,

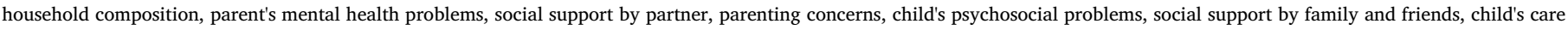
use.

e The order in which a variable was removed from the adjusted model was cultural identity, parent's educational level, child's chronic health problem, child's age, child's gender household composition, parent's mental health, partner's social support, parenting concerns, child's psychosocial problems, social support by family and friends, child's care use.

high social support and high care use. This contrasts with findings in the general population of an inverse relationship, in which less social support is associated with greater care use (Nanninga et al., 2015). This contrast may prove to be a key factor for identifying multiproblem families in psychosocial care.

\subsection{Implications for research}

Our research shows that Andersen and Newman's framework provides a suitable framework for understanding care use by multiproblem families. Our findings show that not only need factors, but also predisposing and enabling factors are relevant for understanding use of care by multiproblem families. The consideration of these additional factors enhances the understanding of care use of these families. As spendings on these families account for a large portion of services' budgets, special attention should be paid to factors associated with their use of several different care services. To gain greater insight into the factors underlying care use by multiproblem families, we recommend that a follow-up study is conducted. Future research should also make an effort to include fathers in the study to ensure their views on child and family functioning are also represented. This study gives insight into the mechanisms of care seeking behavior for multiproblem families. Qualitative design could help to understand these mechanisms, especially with regard to the intergenerational transmission and high level of care use of these families. This intergenerational aspect could also be further investigated with accommodation of the parent-child dyadic structure in the analyses.

"Multiproblem family" is an all-purpose term that has no clear definition or conceptualization. The formulation of a clear set of characteristics to identify these families for research will improve our overall understanding of multiproblem families (Bodden \& Dekovic, 2015).

\section{Conclusion}

This study shows that care use by children in multiproblem families is associated with need factors (parenting concerns and the child's psychosocial problems); a predisposing factor (the child's age); and an enabling factor (the provision of social support by family and friends). Care use of parents of multiproblem families is related to the predisposing factor adverse life events. With its predisposing, enabling and need factors, the Andersen and Newman model adds to our understanding of care use by these families, and may lead to further understanding of the pathways leading to these families' care use. Inadequate use of social support may add to high care use. Assessing the presence of predisposing and enabling factors will add to the early identification of multiproblem families. 


\section{Authors' contributions}

NP was actively involved throughout all the different stages of this research, from study design and data interpreting to drafting the manuscript. PK was responsible for preparing the study, study design, data collection, analysis and drafting of the manuscript. KM and MC made substantial contributions to the development of the theoretical framework of care use, the questionnaire and the recruitment of respondents. MT contributed to the theoretical framework and analyses of the data. Finally, both MN and SR oversaw the interpreting of data and drafting of the manuscript. All authors approved the final version for publication and agree to be accountable for all aspects of the study in which they were involved.

\section{Declaration of conflicts of interest}

1. Noortje Pannebakker declares no conflict of interest

2. Paul Kocken declares no conflict of interest.

3. Meinou Theunissen declares no conflict of interest.

4. Krista van Mourik declares no conflict of interest.

5. Matty Crone declares no conflict of interest.

6. Mattijs Numans declares no conflict of interest.

7. Sijmen Reijneveld declares no conflict of interest.

\section{Acknowledgements}

First and foremost, we thank the parents for participating in this study. We are grateful for the preventive healthcare workers at the Preventive Child Health Care services in The Hague and to the caseworkers of BKK, MEE and Bureau Jeugdzorg in the Hollands Midden region parents for recruiting the parents. We thank research assistants Ellen Westhoff, Jasper Boerrigter, Sophie Wins and Rosanne Schoorl for their work on this project, Yvonne Schonbeck for her support in the project organization, and Paula van Dommelen for the multiple imputation of the data. Finally, we thank Mascha Kamphuis for the project management.

\section{Funding}

This work was supported by the Netherlands Organisation for Health Research and Development (15901.0005) (ZonMW), The Netherlands.

\section{References}

Andersen, R., \& Newman, J. F. (1973). Societal and individual determinants of medica care utilization in the United States. The Milbank Memorial Fund Quarterly, 51(1), 95-124.

Appleyard, K., Egeland, B., van Dulmen, M. H. M., \& Sroufe, L. A. (2005). When more is not better: The role of cumulative risk in child behavior outcomes. Journal of Child Psychology and Psychiatry, and Allied Disciplines, 46(3), 235-245. http://dx.doi.org/ 10.1111/j.1469-7610.2004.00351.x.

Bodden, D. H., \& Dekovic, M. (2015). Multiproblem families referred to youth mental health: What's in a name? Family Process. http://dx.doi.org/10.1111/famp.12144.

Briggs-Gowan, M. J., Carter, A. S., Irwin, J. R., Wachtel, K., \& Cicchetti, D. V. (2004). The brief infant-toddler social and emotional assessment: Screening for social-emotional problems and delays in competence. Journal of Pediatric Psychology, 29(2), 143-155.

Bruns, E. J., Burchard, J. D., \& Yoe, J. T. (1995). Evaluating the Vermont system of care: Outcomes associated with community-based wraparound services. Journal of Child and Family Studies, 4(3), 321-339.

CBS (2014). The Netherlands. Parents give child health centres a 7 out of 10 . Retrieved from www.cbs.nl/en-gb/news/2014/44/parents-give-child-health-centres-a-7-outof-10/, Accessed date: 11 March 2017.

De Wolff, M. S., Theunissen, M. H. C., Vogels, A. G. C., \& Reijneveld, S. A. (2013). Three questionnaires to detect psychosocial problems in toddlers: A comparison of the BITSEA, ASQ:SE, and KIPPPI. Academic Pediatrics, 13(6), 587-592. http://dx.doi.org/ 10.1016/j.acap.2013.07.007

Denholm, R., Power, C., Li, L., \& Thomas, C. (2013). Child maltreatment and household dysfunction in a British birth cohort. Child Abuse Review, 22(5), 340-353. http://dx. doi.org/10.1002/car.2235.

Donga, M., Andaa, R., Felitti, V., \& Dubea, S. (2004). The interrelatedness of multiple forms of childhood abuse, neglect, and household dysfunction. Child Abuse \& Neglect,
$28,771-784$.

Fernandez, E. (2007). Supporting children and responding to their families: Capturing the evidence on family support. Children and Youth Services Review, 29(10), 1368-1394. http://dx.doi.org/10.1016/j.childyouth.2007.05.012.

Finkelhor, D., Ormrod, R. K., \& Turner, H. A. (2007). Poly-victimization: A neglected component in child victimization. Child Abuse and Neglect, 31(1), 7-26. http://dx.doi. org/10.1016/j.chiabu.2006.06.008.

Ford, T., Hamilton, H., Meltzer, H., \& Goodman, R. (2008). Predictors of service use for mental health problems among British school children. Child and Adolescent Mental Health, 13(1), 32-40. http://dx.doi.org/10.1111/j.1475-3588.2007.00449.x.

Ghosh Ippen, C., Harris, W. W., Van Horn, P., \& Lieberman, A. F. (Jul 2011). Traumatic and stressful events in early childhood: Can treatment help those at highest risk? Child Abuse \& Neglect, 35(7), 504-513.

Goerge, R. M., Smithgall, C., Seshadri, R., \& Ballard, P. (Eds.). (2010). Illinois families and their use of multiple service systems. Chicago: Chapin Hall at the University of Chicago.

Goldberg, D., \& Huxley, P. (1980). The pathway to psychiatric care: Mental illness in the community. London: Tavistock Publications.

Goodman, R. (1997). The strengths and difficulties questionnaire: A research note. Journal of Child Psychology and Psychiatry, and Allied Disciplines, 38(5), 581-586.

Hakkaart-Van Roijen, L., Van Straten, A., Donker, M., \& Tiemens, B. (2002). Institute for Medical Technology Assessment. In Erasmus Universiteit Rotterdam (Ed.). Trimbos/ iMTA questionnaire for costs associated with psychiatric illness (TiC-P). Rotterdam.

Hayden, C., \& Jenkins, C. (2014). 'Troubled families' programme in England: 'Wicked problems' and policy-based evidence. Policy Studies, 35(6), 631-649. http://dx.doi. org /10.1080/01442872.2014.971732.

Hayden, C., \& Jenkins, C. (2015). Children taken into care and custody and the 'troubled families' agenda in England. Child \& Family Social Work, 20(4), 459-469. http://dx. doi.org/10.1111/cfs.12095.

Hughes, K., Bellis, M. A., Hardcastle, K. A., Sethi, D., Butchart, A., Mikton, C., \& Dunne, M. P. (2017). The effect of multiple adverse childhood experiences on health: A systematic review and meta-analysis. The Lancet Public Health, 2(8), e356-e366. http://dx.doi.org/10.1016/S2468-2667(17)30118-4.

IBM Corp (2011). IBM SPSS statistics for windows 20.0. Armonk, NY: IBM Corp.

Koeter, M. W. J., \& Ormel, J. (1991). General health questionnaire, Nederlandse bewerking. Handleiding. Lisse: Swets \& Zeitlinger.

Kruizinga, I., Jansen, W., de Haan, C. L., van der Ende, J., Carter, A. S., \& Raat, H. (2012) Reliability and validity of the Dutch version of the brief infant-toddler social and emotional assessment (BITSEA). PLoS One, 7(6).

Lucas, P. J., McIntosh, K., Petticrew, M., Roberts, H. M., \& Shiell, A. (2008). Financial benefits for child health and well-being in low income or socially disadvantaged families in developed world countries. Cochrane Database of Systematic Reviews(8).

Matos, A. R., \& Sousa, L. M. (2004). How multiproblem families try to find support in social services. Journal of Social Work Practice, 18(1), 65-80.

Morris, K. (2013). Troubled families: Vulnerable families' experiences of multiple service use. Child and Family Social Work, 18(2), 198-206. http://dx.doi.org/10.1111/j. 1365-2206.2011.00822.x

Nanninga, M., Jansen, D. E. M. C., Knorth, E. J., \& Reijneveld, S. A. (2015). Enrolment of children and adolescents in psychosocial care: More likely with low family social support and poor parenting skills. European Child and Adolescent Psychiatry, 24(4), 407-416. http://dx.doi.org/10.1007/s00787-014-0590-3.

NJI (2011). The Netherlands. Youth and Family_Centres in The Netherlands. Retrieved from www.nji.nl/nl/Download-NJi/PublicatieNJi/Youth and Family Centres in The_Netherlands.pdf/, Accessed date: 11 March 2017.

Norman, R. E., Byambaa, M., De, R., Butchart, A., Scott, J., \& Vos, T. (2012). The longterm health consequences of child physical abuse, emotional abuse, and neglect: A systematic review and meta-analysis. PLoS Medicine, 9(11), http://dx.doi.org/10. 1371/journal.pmed.1001349.

Raphael, J. L., Zhang, Y., Liu, H., \& Giardino, A. P. (2010). Parenting stress in US families: Implications for paediatric healthcare utilization. Child: Care, Health and Development 36(2), 216-224. http://dx.doi.org/10.1111/j.1365-2214.2009.01052.x.

Rubin, D. (1987). In New York W (Ed.). Multiple imputation for nonresponse in surveys.

Sacco, F. C., Twemlow, S. W., \& Fonagy, P. (2008). Secure attachment to family and community: A proposal for cost containment within high user populations of multiple problem families. Smith College Studies in Social Work. http://dx.doi.org/10.1300/ J497v77n04 03.

Sociaal Cultureel Planbureau (2015). Social economic status. Retrieved from www.scp. nl/english/, Accessed date: 18 August 2015.

Sousa, L. (2005). Building on personal networks when intervening with multi-problem poor families. Journal of Social Work Practice, 19(2), 163-179. http://dx.doi.org/10. 1080/02650530500144766.

Sousa, L., \& Rodrigues, S. (2009). Linking formal and informal support in multiproblem low-income families: The role of the family manager. Journal of Community Psychology, 37(5), 649-662. http://dx.doi.org/10.1002/jcop.20313.

Stahmer, A. C., Leslie, L. K., Hurlburt, M., Barth, R. P., Webb, M. B., Landsverk, J., \& Zhang, J. (2005). Developmental and behavioral needs and service use for young children in child welfare. Pediatrics, 116(4), 891-900. http://dx.doi.org/10.1542/ peds.2004-2135.

Stith, S. M., Liu, T., Davies, L. C., Boykin, E. L., Alder, M. C., \& Harris, J. M.\& Dees, J. E. M E. G. (2009). Risk factors in child maltreatment: A meta-analytic review of the literature. Aggression and Violent Behavior, 14(1), 13-29. http://dx.doi.org/10.1016/j. avb.2006.03.006.

Tausendfreund, T., Knot-Dickscheit, J., Post, W. J., Knorth, E. J., \& Grietens, H. (2014), Outcomes of a coaching program for families with multiple problems in the Netherlands: A prospective study. Children and Youth Services Review, 46, 203-212. http://dx.doi.org/10.1016/j.childyouth.2014.08.024.

Tausendfreund, T., Knot-Dickscheit, J., Schulze, G. C., Knorth, E. J., \& Grietens, H. 
(2016). Families in multi-problem situations: Backgrounds, characteristics, and care services. Child and Youth Services, 37(1), 4-22. http://dx.doi.org/10.1080/0145935X. 2015.1052133.

Theunissen, M. H. C., Vogels, A. G. C., De Wolff, M. S., \& Reijneveld, S. A. (2013). Characteristics of the strengths and difficulties questionnaire in preschool children. Pediatrics, 131(2), e446-e454.

Tick, N. T., Van Der Ende, J., \& Verhulst, F. C. (2008). Ten-year increase in service use in the dutch population. European Child and Adolescent Psychiatry, 17(6), 373-380.

Travassos, C., Viacava, F., Pinheiro, R., \& Brito, A. (2002). Utilization of health care services in brazil: Gender, family characteristics, and social status. Revista Panamericana De Salud Publica/Pan American Journal of Public Health, 11(5-6), 365-373.

van Buuren, S. (2012). Flexible imputation of missing data. Boca Raton: Chapman \& Hall/
CRC Press 342

Van der Ploeg, J. D., \& Scholte, E. M. (2008). Handleiding vragenlijst gezinsfunctioneren (GVL) Houten: Bohn Stafleu Van Loghum.

Verhulst, F. C., \& Van Der Ende, J. (1997). Factors associated with child mental health service use in the community. Journal of the American Academy of Child and Adolescent Psychiatry, 36(7), 901-909.

Wölfle, S., Jost, D., Oades, R., Schlack, R., Hölling, H., \& Hebebrand, J. (2014). Somatic and mental health service use of children and adolescents in Germany (KiGGS-study). European Child and Adolescent Psychiatry, 23(9), 753-764. http://dx.doi.org/10. 1007/s00787-014-0525-z.

Zeijl, E., Crone, M., Wiefferink, K., Keuzenkamp, S., \& Reijneveld, M. (2005). Kinderen in Nederland. Den Haag: Sociaal en Cultureel Planbureau (SCP). 